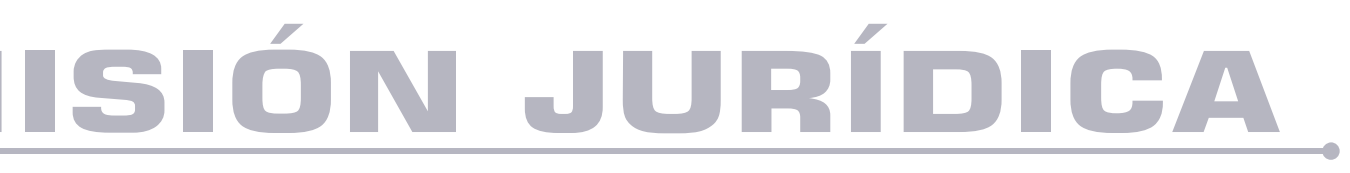

\title{
O modelo regulatório brasileiro: comentários à Lei Geral das Agências Reguladoras
}

El modelo reglamentario brasileño: comentarios sobre la Ley general de las Agencias Reglamentarias

Autores: Henrique Savonitti Miranda, Jonas Rodrigo Gonçalves, Marcus Vinicius Barbosa Siqueira DOI: https://doi.org/10.25058/1794600X.1748 


\title{
O MODELO REGULATÓRIO BRASILEIRO: COMENTÁRIOS À LEI GERAL DAS AGÊNCIAS REGULADORAS*
}

\author{
The Brazilian regulatory model: comments on the law General \\ General law of agencies Regulatory agencies \\ El modelo reglamentario brasileño: comentarios sobre la Ley \\ general de las Agencias Reglamentarias
}

$\begin{array}{r}\text { MSc. Henrique Savonitti Miranda }{ }^{a} \\ \text { henrique.miranda@institutoprocessus.com.br } \\ \text { MSc. Jonas Rodrigo Gonçalves } \\ \text { professorjonas@gmail.com }\end{array}$
Marcus Vinicius Barbosa Siqueirac
maarcus.siqueira@hotmail.com
Fecha de recepción: 4 de junio de 2020
Fecha de revisión: 14 de julio de 2020
Fecha de aceptación: 23 de julio de 2020

\section{RESUMO}

As agências reguladoras surgiram no Brasil com o propósito de regular as atividades econômicas transferidas à iniciativa privada, a partir de reformas promovidas no cenário econômico nacional, após a implementação de planos de desburocratização da máquina estatal. Para a empreitada,

\footnotetext{
* Este artigo se constitui como fruto de pesquisas do grupo de estudos "Direito e Políticas Públicas", que existe na Faculdade Processus (em Brasília, capital do Brasil) desde 2012, sob coordenação do professor Jonas Rodrigo Gonçalves, decano da Instituição. Este grupo de pesquisa integra a Coordenação de Pesquisa e Iniciação Científica da Faculdade Processus, do qual fazem parte o professor Jonas Rodrigo Gonçalves e o estudante Marcus Vinicius Barbosa Siqueira. A Faculdade Processus se destaca por sua sólida política de pesquisa institucional, que integra todos os seus cursos, com linhas de pesquisa institucionais que norteiam toda a produção científica, a partir do referencial "Políticas Públicas e Desenvolvimento Social". A elaboração deste trabalho contou com a participação externa do professor Henrique Savonitti Miranda, estudioso da temática que envolve este artigo.

a. Doutor em Direito pela Universidade de Udine, Itália, e pela Universidade de Toulon, França. Mestre em Direito Administrativo e Gestão Pública pela Università La Sapienza, de Roma, Itália. Mestre em Direito Empresarial pela Universidade de Franca. Especialista em Direito Tributário pelo IBET/PUC-SP e IBDT/USP. Bacharel em Direito pela Faculdade de Direito de São Carlos. Advogado com inscrições na Ordem dos Advogados do Brasil (Seções de São Paulo, Goiânia e Brasília), de Portugal (Regional de Lisboa) e de Udine, Itália. Professor da Faculdade Processus nas disciplinas de Introdução ao Estudo do Direito, Teoria Geral do Direito, Direito Constitucional II e Direito Administrativo II. Lattes: http://lattes.cnpq.br/7210345879445236

b. Doutorando em Psicologia pela Universidade Católica de Brasília - DF (UCB); Mestre em Ciência Política (Direitos Humanos e Políticas Públicas); Licenciado em Filosofia e Letras (Português e Inglês); Especialista em Direito Constitucional e Processo Constitucional, em Direito Administrativo, em Direito do Trabalho e Processo Trabalhista, entre outras especializações. Professor das faculdades Processus (DF), Unip (SP) e Facesa (GO). Escritor (autor de 61 livros didáticos/acadêmicos). Revisor. Editor. CV Lattes: http://lattes.cnpq.br/6904924103696696. ORCID: https://orcid.org/0000-0003-4106-8071.

c. Graduando em Direito pela Faculdade Processus (Brasília/DF). Autor de artigos pelo Grupo de Pesquisa Direito e Políticas Públicas, sob coordenação do professor MSc. Jonas Rodrigo Gonçalves, entre os quais estão "A Segurança Pública no Brasil" e "Políticas Públicas, Meio Ambiente e Justiça". Palestrante no I Congresso Internacional de Políticas Públicas e Desenvolvimento Social da Faculdade Processus (2019). Lattes: http://lattes.cnpq.br/8097318457599087
} 
buscou-se a importação de modelos estrangeiros para as agências, em especial a dos países que também tinham laços com uma economia mais liberal que se erguia no Brasil, a exemplo dos Estados Unidos da América. Para tanto, houve um esforço para que se adequasse o modelo das agências ao ordenamento jurídico nacional, em que, apesar das peculiaridades de cada sistema legal no mundo, o Brasil segue com o modelo das agências reguladoras, que já se encontram absorvidas no cenário socioeconômico.

\section{PALAVRAS-CHAVE:}

Agência Reguladora; Sistema Legal; Civil Law/ Common Law.

\section{ABSTRACT}

Regulatory agencies appeared in Brazil with the purpose of regulating the economic activities transferred to the private initiative, based on reforms promoted in the national economic scenario, after the implementation of plans to reduce the bureaucracy of the state machine. For the contract, foreign models for the agencies were imported, especially from the countries that also had ties with a more liberal economy, which rose in Brazil such as the United States of America. For this purpose, an effort was made to adapt the agency model to the national legal system. Thus, despite the peculiarities of each legal system in the world, Brazil still follows the model of regulatory agencies, which are already absorbed in the socioeconomic scenario.

\section{KEY-WORDS:}

Regulatory Agency; Legal System; Civil Law/ Common Law.

\section{RESUMEN}

Las agencias reguladoras aparecieron en Brasil con el propósito de regular las actividades económicas transferidas al sector privado, con base en reformas promovidas en el escenario económico nacional, posterior a la implementación de planes encaminados a reducir la burocracia de la máquina estatal. Para el contrato, se importaron modelos para las agencias, especialmente de los países que también tenían vínculos con la economía más liberal que surgió en Brasil, como la de los Estados Unidos de América. Con este fin, se hizo un esfuerzo por adaptar el modelo de agencias al sistema legal nacional, en el cual, a pesar de las peculiaridades de cada sistema legal en el mundo, Brasil sigue con el modelo de agencias reguladoras, ya absorbidas en el escenario socioeconómico.

\section{PALABRAS CLAVE}

Agencia reguladora; Sistema legal; Derecho civil / Derecho común.

\section{INTRODUÇÃO}

As agências reguladoras, no Brasil, surgiram a partir das reformas implementadas no cenário econômico nacional, mais especificamente nos anos de 1990, possibilitando um novo modelo de intervenção do Estado na propriedade privada, em que o ente estatal passa de executor direto das atividades econômicas para mero espectador e regulador da atividade privada. A importação do modelo das agências reguladoras, também, se relaciona ao novo modelo de política econômica adotado no país após a promulgação da Constituição Federal de 1988.

Certamente, a adequação de um modelo estrangeiro, baseado em normas alienígenas, é o principal problema no estudo das agências. Essa adequação deixa lacunas legislativas, que precisam ser preenchidas pelos operadores do Direito, para que a atividade regulatória no Brasil possa ser eficiente e com padrões aceitáveis a nível internacional.

Cada país se vale de um sistema jurídico diverso e isso se justifica pelas peculiaridades locais, históricas e culturais de cada nação. Assim, as agências reguladoras brasileiras foram fortemente influenciadas pelas agências norteamericanas, apesar destas serem insculpidas a partir do modelo da Common Law, enquanto aquelas, a Civil Law. Com a globalização e a crescente utilização do Direito Comparado para produção da legislação nacional, faz-se necessário a reflexão acerca dos sistemas jurídicos legais, que cada vez mais são relativizados em prol da segurança jurídica (SAVONITTI MIRANDA, 2019, p. 21).

Dessa forma, a demonstração do modelo regulatório no Brasil e sua adequação ao sistema jurídico nacional constituem objetivos neste 
ensaio. 0 modelo econômico adotado no país teve forte impacto sobre o desenvolvimento das agências reguladoras e o motivo pelo qual houve seu espelhamento acerca do modelo norte-americano.

Ademais, o estudo do Direito Regulatório é de grande valia pois diz respeito à aspectos econômicos do país. Uma regulação eficaz dos setores econômicos contribui para o desenvolvimento socioeconômico, influencia a desburocratização do aparelho estatal e incentiva a livre iniciativa.

\section{BREVES CONSIDERAÇõES HISTÓRICAS}

Historicamente, os bens e serviços públicos sempre foram tratados pelo Estado como sendo de relevante valor social ou imprescindíveis à Segurança Nacional, razão pela qual sempre foram exercidos pelos entes públicos de direito privado, como empresas públicas e sociedades de economia mista, ou, até, diretamente pelo Estado. Contudo, principalmente com o advento da Constituição de 1988, essa concepção foi mudada, dando lugar à nova economia que surgira no país, que preza pela eficiência dos serviços prestados, considerando-se, ainda, a falta de recursos e baixa qualidade dos administradores que então geriam a coisa pública. Nasce, assim, uma crescente necessidade de importação de modelos gerenciais administrativos inspirados no setor privado para obtenção de melhores resultados para a população.

Nesse cenário, foi criado o terreno para o surgimento das Agências Reguladoras, entidades estatais de natureza autárquica, dotadas de personalidade jurídica e autonomia em relação aos órgãos centrais do Estado, possuindo como função precípua a regulamentação econômica de áreas de interesse do Estado. Essa regulamentação engloba o exercício de atividades típicas Estatais, como normatização e exercício do poder de polícia, por meio de atos de império, atributos do Direito Administrativo que servem para a regulamentação de setores que eram, até o período anterior à Constituição Federal de 1988, de monopólio exclusivo do Estado. (CARVALHO FILHO, 2013, p. 75)

Nota-se, com isso, que a flexibilização do monopólio estatal foi um dos fatores primordiais para a mudança de paradigmas na economia brasileira, conforme explica Luís Roberto Barroso:
A segunda Linha de reformas que modificaram a feição da ordem econômica brasileira foi a chamada flexibilização dos monopólios estatais. A Emenda Constitucional $\mathrm{n}^{\circ} 5$, de 15/08/1995, alterou a redação do $\S 2^{\circ}$ do art. 25, abrindo aos Estadosmembros concederam às empresas privadas a exploração dos serviços públicos locais de distribuição de gás canalizado, que anteriormente, só podiam ser delegados a empresas sob controle acionário estatal. 0 mesmo se passou com relação aos serviços de telecomunicações e de radiodifusão sonora e de sons e imagens. (BARROSO, 2002, p. 289) (grifos no original)

Interessante observar que a reforma constitucional, que possibilitou a transformação no modelo econômico, incidiu, sobretudo, em setores bastantes sensíveis aos governantes e à população, a exemplo do petróleo e gás natural. Referido campo não ficou de fora do plano de reforma e contribuiu, de grande modo, para a entrada, no mercado nacional, de multinacionais estrangeiras (BARROSO, 2002, p. 289). Dessa forma, foi possível a instituição de um novo marco para a noção de regulação, que não era propriamente nova no Brasil, a considerar entes que já haviam uma função similar, como o Banco Central e o Conselho Monetário Nacional, dentre outros, mas que trouxeram a concepção estrangeira de regulação, que teve impactos no ordenamento jurídico (SOUTO, 1999, p. 131).

À vista disso, a partir das referidas ações de privatização - ou seja, a atribuição ao mercado da titularidade da exploração de atividades econômicas, deixando ao Estado apenas a atuação considerada como "necessária aos imperativos da segurança nacional ou a relevante interesse coletivo", nos termos do art. 173 da atual Constituição da República - surge o movimento de "agencificação", que se refere não só a quantidade de agências atualmente existentes a partir do modelo trazido ao Brasil na década de 1990, mas também a uma mudança do modo de operação, com advento de novo padrão regulatório (RAMALHO, 2009, p. 54).

Com a alteração de entendimento sobre o modelo econômico a ser adotado no país, mudase o pensamento político para adequação ao preceito normativo disposto no referido art. 
173 da Constituição Federal, em que atividades anteriormente consideradas necessárias à segurança nacional ou de relevante interesse público, que permitiam a exploração, como monopólio, por parte do Estado, perderam este status e puderam ser delegadas ao setor privado. Trata-se, assim, de análise de conveniência $e$ oportunidade em que caberá à Administração o estudo da utilidade da participação ou não na iniciativa privada e os impactos econômicos e sociais para os interessados (CARNEIRO, 2006, p. 199).

As reformas econômicas promovidas na Constituição de 1988 tiveram a finalidade de dar mais eficiência à prestação dos serviços públicos. Para isso, o Governo Federal criou o Plano Diretor de Reforma do Aparelho do Estado. Tal medida era baseada em 4 pilares fundamentais, que se dividiam em núcleos administrativos do Estado, a saber: (I) o núcleo estratégico, que compunha a administração direta e tido por burocrático, além de alcançar as três funções estatais (Executivo, Legislativo e Judiciário); (II) o núcleo de atividades exclusivas, que tratava sobre aquelas atividades tipicamente estatais e que eram exercidas por entidades da administração indireta, ou seja, "braços" da administração descentralizados, com personalidade jurídica própria, como autarquias e fundações públicas; (III) os serviços não exclusivos do Estado, como saúde (art. 197/CF) e educação (art. 209), consistindo em atividades que poderiam ser delegadas ao setor privado para exploração, com ou sem fins lucrativos; e (IV) a produção de bens e serviços para o mercado, onde o Estado atuará apenas de forma subsidiária, nos termos do supracitado art. 173 da CF/88. Referido programa, teve a função de atribuir mais celeridade às atividades da administração, além de contribuir para o novo modelo econômico que surgia (SAVONITTI MIRANDA, 2007a, pp. 125127; NOHARA, 2018, p. 665; BRESSER-PEREIRA, 2000, pp. 14-17).

Nesse diapasão de delegação à iniciativa privada, com reformas, desestatizações e privatizações, ergue-se o dever ao Estado de fiscalização das atividades delegadas à iniciativa privada. Eis que, nesse momento, o papel estatal passa a englobar defesa da livre concorrência, prestação do serviço público e políticas de mercado, além da definição de regras acerca de assuntos técnicos do setor. 0 Estado-Regulador é resultado, por conseguinte, da nova ideologia econômica e política que passou a vingar e se sobressair no então cenário social.

Sendo assim, as agências devem ter a capacidade de exercer, de forma plena, o poder de polícia e regulamentar sobre quem exerce a atividade delegada, com poderes de intervenção econômica sobre o serviço regulado, além do poder de definir estratégias de livre concorrência e possibilidade de dar ao setor regulado maior competitividade, sem deixar de lado o serviço prestado à população, além de segurança quanto à agenda regulatória a ser desenvolvida pela entidade fiscalizadora.

\section{ASPECTOS INTRODUTÓRIOS DO DIREITO REGULATÓRIO E ECONÔMICO}

Nessa seara, não há como negar a influência internacional sobre as questões econômicas e sobre o Direito, sendo possível notar um estreito vínculo entre a ciência jurídica e a economia, o que também influiu à criação das agências reguladoras. A fiscalização de áreas de relevante interesse, inclusive internacional, como transportes, vigilância sanitária, energia, combustíveis, fazem com que as agências tenham conexões internacionais, até mesmo, com organismos multinacionais, para edição de normas que são recepcionadas pelos Estados nacionais. 0 caráter mundial dos agentes privados que compõem os setores de infraestrutura, que foram especialmente delegados à iniciativa privada, também explica o aspecto internacional das agências.

A economia moderna e globalizada se contrapõe à regulação nacional por seus agentes e à criação de normas de caráter nacional, típica do exercício da soberania nacional, mas que deve ser flexibilizada com vistas à adaptação à nova realidade econômica. Assim, as agências devem ser capazes de se impor sobre o setor regulado, não permitindo interferências e pressões políticas, sob pena de restarem prejudicadas e sem efetividade as atividades fiscalizadoras. Observase, pois, que a própria globalização exige uma regulamentação uniforme do setor privado que atua internacionalmente. (TOMAZETTE, 2014, p. 67).

A ordem econômica, deste modo, possibilitou a prestação de serviços que eram de responsabilidade estatal, mas que não eram aplicados em razão da ineficiência e da falta de 
capacidade do Estado para prover os serviços públicos, seja pela falta de responsabilidade da gestão dos recursos para a área, seja pela simples falta dos referidos recursos que, de fato, são escassos. Dessa forma, Direito e Economia se mesclam em uma relação simbiótica, com a interpretação de normas, principalmente as regulatórias, observando o fim econômico. Ressalta-se que, em tal atividade hermenêutica, não deve haver a prevalência de uma ciência sobre a outra, mas sim a junção de institutos, haja vista a regulamentação econômica moderna instituir esse dever, principalmente, para a elaboração de normas, o que é feito pelos próprios entes fiscalizadores. (RAMALHO, 2009, p. 32 e 33).

Com efeito, a Constituição de 1998 inaugurou uma nova forma de economia, até então inédita no Brasil, inspirada em países da Europa e dos Estados Unidos, com descentralização econômica e possibilitando ao Estado a exploração do setor privado apenas de forma subsidiária, e não como protagonista, como era de costume desde os tempos coloniais. Ao mesmo tempo, a Carta da República não deixou desprotegidos os direitos sociais e o cumprimento da função social da propriedade, que é obrigação basilar de todos os que possuem os chamados Direitos Reais. Miguel Reale Júnior analisa que:

(...) esta atuação do Estado como agente normativo ou regulador é de ser concretizada com respeito aos princípios que regem a ordem econômica, fundada na valorização do trabalho humano e na livre iniciativa, visando a assegurar a todos uma existência digna, conforme os ditames da justiça social (art. 170 da CF)"(REALE JÚNIOR, 1992. p. 8).

Neste cenário, Diogo de Figueiredo Moreira Neto divide a intervenção do Estado na economia em (I) regulatória, se referindo a edição de normas de caráter cogente para o setor regulado, com análises de impacto regulatório, por parte do ente fiscalizador e da real efetividade da regulação; (II) concorrencial, se tratando da defesa da concorrência entre as entidades privadas reguladas, a fim, inclusive, de melhora na prestação dos serviços à população. Neste tópico, deve-se ressaltar que as agências reguladoras não funcionam como entidades de proteção ao consumidor, como se pode pensar no senso comum, mas como agentes defensores da prestação do serviço de qualidade e, ao mesmo tempo, do desenvolvimento econômico do País, por meio de políticas regulatórias e incentivos aos regulados; (III) sancionatória, que impõe ao regulado punições pelo descumprimento de normas regulatórias. Essa atuação é importante porque se relaciona a um objetivo estatal, que foi descumprindo, gerando ao Estado pretensão punitiva hábil a constranger o cometimento de novas irregularidades (MOREIRA NETO, 1996, p. 365).

Oportuno atentar para o fato de que, no âmbito regulatório das agências, forma-se uma espécie de direito negociado, em que as normas criadas são debatidas pelos próprios regulados, e com a sociedade, em geral, por meio da realização de audiências públicas, consultas públicas e análises de mercado. Por isso, deve haver um consenso dos interessados sobre a regulação, daí as legislações mais modernas que tratam das agências trazerem normas definindo diretrizes como a "regulação responsiva" e a "análise de impacto regulatório", mostrando que o ponto de vista econômico dos regulados também constitui aspecto importante e necessário no processo (DI PIETRO, 2018, p.57).

Salienta-se, ainda, a atividade de fomento que algumas agências exercem, com um papel de investimentos e incentivos ao regulado, com o intuito de desenvolvimento do setor, o que também traz impactos sobre a atividade econômica e institui normas a serem observadas pelos agentes privados que prestam serviços de interesse público. As agências possuem a função de, além disso, aumentar a competitividade no setor, estimulando fenômenos econômicos, como o da concorrência, a fim de propiciar a melhoria na qualidade da prestação de serviços aos usuários (GROTTI, 2004, p. 73). Ressalta-se, ainda, o papel das agências em tornar referido serviço, principalmente, mais democrático, possibilitando, cada vez mais, maior acesso de pessoas.

\section{AS AGÊNCIAS NORTE-AMERICANAS E A COMMON LAW}

Como se sabe, o sistema Legal da Common Law tem a sua base sistêmica-jurídica no precedente judiciário (jurisprudência), e não na legislação rígida típica do sistema romano-germânico de Direito (PALMA, 2019, p. 126). Isso teve forte impacto sobre o funcionamento das agências reguladoras no momento de sua introdução no direito brasileiro que, com sua natureza diversa, 
teve de se adequar, gerando algumas controvérsias e limitações ao modelo originalmente pensado e formulado, com maior destaque, aos Estados Unidos da América.

Anote-se que essa introdução de instituições e teorias jurídicas originadas de modelos estrangeiros é comum, em especial, no âmbito do Direito Administrativo, que, por sua peculiar característica, mesmo no sistema rígido-legal de base romanística, impõe severas dificuldades a aprovação de um código que estruture todas as suas normas de forma compilada, seja devido à natureza Federativa do Estado brasileiro, seja por conta do próprio princípio constitucional da legalidade administrativa (art. $37 \mathrm{da} C \mathrm{~F} / 88$ ), o que limitaria, a ponto insustentável, a atuação da administração pública nacional.

Assim, muitos passaram a considerar um obstáculo ao desenvolvimento da referida disciplina legal, na seara nacional, o próprio sistema romano e os princípios que nortearam o Direito Administrativo brasileiro desde os tempos de sua criação (OLIVEIRA, 2009, p. 159). É certo, outrossim, que cada vez mais, o Direito brasileiro recebe influências externas e se mescla aos sistemas voltados à jurisprudência como forma de consolidação de regras e posicionamentos jurídicos, gerando uma relação composta entre os dois sistemas, com o propósito, sobretudo, de gerar segurança jurídica à sociedade.

Como no Brasil, o cenário econômico dos Estados Unidos influenciou fortemente à criação das agências, sendo constituídas como independent regulatory agencies, a partir de um movimento de regulamentação de setores da economia, pautado, principalmente, no período da década de 30, durante o governo Roosevelt. Com isso, foi criado o Administrative Procedure Act, norma de caráter infraconstitucional que caracteriza as agências como autoridades do governo federal diversas dos Poderes Judiciário e Legislativo, estando assim, fora da repartição clássica dos três poderes. Referida norma prescrevia que os órgãos que não fizessem parte de um dos poderes constituídos, seriam, necessariamente, do universo regulador, consistindo, portanto, em um critério exclusivo adotado pelo legislador norte-americano (ARAGÃO, 2013, p. 230).

A justificativa para a existência das agências, à vista disso, consistiria em criar entes, distintos das funções clássicas do Estado, e autônomos ou seja, sem sofrer influência política, em tese, e com relativa independência para a tomada de decisões e gestão dos próprios recursos dotados de grande especialização em suas áreas de exercício, sendo-lhes atribuído alto gral de discricionariedade técnica, estando, assim, fora do arcabouço de alcance de mérito do Poder Judiciário (MATOS; COSTA; XAVIER, 2005, p. 2).

Alguns desses conceitos perduram ainda hoje nas agências reguladoras, mesmo nas brasileiras, como os conceitos de mérito administrativo, o princípio da especialidade técnica das agências e a sua autonomia, que também são garantidos por Lei. Entretanto, nos Estados Unidos, o modelo, que é muito mais pulsante, começou a sofrer críticas, justamente pela ampla autonomia conferida às agências, fazendo-as alvos de ataques dos próprios regulados que, com o fim de obter o controle sobre o ente regulador, exerciam pressão política e econômica para a obtenção de benefícios no setor.

Passado o período do New Deal que deu origem às agências, as críticas à sua elevada autonomia e independência se basearam, principalmente, na "teoria da captura", que mostrava os riscos provenientes da possibilidade de "captura" da agência reguladora por parte dos agentes regulados, para satisfação de suas pretensões econômicas no mercado. A Teoria da Captura fez com que a população passasse a desconfiar do modelo jurídico das agências e da presunção de que, simplesmente por deterem conhecimento técnico da matéria, estariam habilitadas à tomada de decisões mais acertadas. (OLIVEIRA, 2009, p. 162). Essa questão precisou ser contornada para que o modelo prosseguisse e viesse, novamente, a obter êxito.

No sistema das agências reguladoras, também há que se destacar o modelo europeu de regulação, que surgiu a partir de 1834, na Inglaterra, onde houve a criação de entes autônomos, criados pelo parlamento e com previsão em Lei. Nesse país, as agências funcionavam com um poder, inicialmente, de mera execução das atividades previstas abstratamente pelas leis. Com o tempo, acumularam a função de, além da executiva, regular a atividade, impor deveres de forma coercitiva e aplicar sanções pelo descumprimento de referidos deveres. (GROTTI, 2004, p. 69). 
Discorrendo sobre a natureza das agências no sistema jurídico estadunidense, leciona DI PIETRO:

Nos Estados Unidos, a Administração Pública é composta por agências com função quase legislativa e quase judicial. E o Direito Administrativo é o conjunto de normas postas pelas agências. A função é quase legislativa porque as agências recebem, por lei, quando criadas, o poder de baixar normas com força obrigatória. Mas a função é quase legislativa porque as normas das agências estão colocadas abaixo das leis na escala hierárquica, podendo ser invalidadas por decisão judicial, quando contrariem as leis, seja por infringência dos standards, princípios, diretrizes contidos na lei (princípio do devido processo legal substantivo), seja por inobservância do processo de elaboração das normas, em que a participação do cidadão constitui exigência obrigatória em várias fases. (DI PIETRO, 2018, p. 56) (grifos no original)

Registre-se que, a função quase judicial das agências, impõe que, muito embora gozem de poder sancionador, capaz de impor aos regulados penalidades e obrigações auto executáveis, e até intervir na propriedade privada "de ofício", caberá sempre o controle de legalidade de seus atos, que poderão ser anulados quando existam vícios irretratáveis (Súmula 346/STF). Este fato advém, também, do modelo de "jurisdição una", ou "jurisdição única" adotado expressamente pelo Constituinte Originário, deixando a cargo do Poder Judiciário a titularidade da verificação de legalidade e constitucionalidade de todos os atos da administração (inciso XXXV do art. $5^{\circ}$ da $\mathrm{CF} / 88$ ), visto que este é o detentor da jurisdição e responsável pelo verificar contradições entre as normas produzidas pelas agências, tidas por materiais e as Leis em sentido Formal.

Tem-se que, nos Estados Unidos, as agências reguladoras possuem uma grande independência em relação ao Legislativo, em sua atividade normativa, que se qualifica de forma especial, em relação às normas editadas pelo congresso, com caráter geral e abstrato (standards). Com relação ao Executivo, este não pode interferir nas decisões de mercado tomadas pelas agências e, ao mesmo tempo, estas possuem uma função arbitral para dirimir conflitos entre os regulados, notadamente os delegatários dos serviços públicos e entre eles e os usuários (NOHARA, 2018, p. 610).

Dessa forma, o modelo norte americano permaneceu, baseado no fundamento basilar da Common Law, o que permitiu que o legislativo delegasse às agências a titularidade do poder de regulamentar sobre a sua matéria de objeto, o executivo à independência das agências e o judiciário, a não interferência nas questões técnicas da matéria regulada (mérito administrativo).

\section{AS AGÊNCIAS NO BRASIL E A CIVIL LAW}

A partir de todo esse movimento regulatório vindo, principalmente, dos Estados Unidos, bem como baseado em seu modelo econômico neoliberal, surge no Brasil as denominadas agências reguladoras, formadas com a natureza de pessoa jurídica de Direito Público, dotada de poderes especiais.

Foram enquadradas pelo legislador no gênero "autarquia". Note-se que a opção escolhida é acertada, tendo em vista suas funções coercíveis, dotadas do jus imperii, fiscalizadora, sancionatória, possuindo a prerrogativa, ainda, de constrição de bens particulares e interventiva nos domínios. Ocorre que o legislador brasileiro não criou um modelo específico, à exemplo dos Estados Unidos, que posicionou as agências em um "status próprio", fora da repartição clássica de poderes, mas as ajustou à organização administrativa brasileira vigente, estabelecida por meio do Decreto-Lei no 200/1967. Em vista disso, só poderiam ser tidas como autarquias (CARVALHO FILHO, 2017, p. 512 e 513).

Dado ao seu caráter de pessoas jurídicas de direito público interno, estão sujeitas aos ditames do art. 37 da Constituição Federal, bem como a todos os princípios, constitucionais e infraconstitucionais, que regem a Administração Pública brasileira. As agências só podem ser criadas por lei, assim como extintas, estando limitadas, inclusive quanto a sua organização, aos preceitos legais. Vê-se que os poderes especiais investidos às agências dão a estas autarquias autonomia administrativa e financeira, além de estabilidade aos seus dirigentes, conferindoos mandatos fixos, sendo uma forma de afastar ingerências políticas em seus assuntos técnicos (BARROSO, 2002, p. 296). Subordinadas aos limites das normas criadas pelo Poder Legislativo, 
as agências possuem a característica ímpar de ditar normas regulamentares sobre assuntos de seus interesses, além de sancionar os entes regulados pelo descumprimento de referidas normas. Com efeito, as agências reguladoras brasileiras podem determinar sanções independentemente de prévia intervenção ou autorização judicial.

Vale mencionar a possibilidade de criação dessas entidades por todas as unidades da federação (União, Estados, Distrito Federal e Municípios), considerando-se o caráter federativo do Brasil, em que a Constituição outorga autonomia administrativa, financeira e legislativa a todos os entes que integram o pacto federativo, cabendo, todavia, a observação dos preceitos constitucionais básicos acerca da sua criação, extinção e organização, que deve se dar por lei, conforme determina o art. 37, inciso XIX, da Carta Maior (SAVONITTI MIRANDA, 2007b, p. 379; CARVALHO FILHO, 2017, p. 512 e 513).

Trazido para o Brasil, o modelo se enquadrou de acordo com a forma econômica que se estabeleceu a partir dos anos de 1990, fazendo com que o legislador fizesse alterações para o enquadramento no arcabouço jurídico nacional. Sabe-se que o sistema legal vigente no Brasil, desde o período colonial, a Civil Law ou sistema romano-germânico, impõe uma maior rigidez normativa, e a impossibilidade de sua transgressão por meios interpretativos. Dessa forma, embora as agências tenham autonomia, não podem ser consideradas como independentes, como ocorre nos Estados Unidos. Com relação ao Executivo, observa-se que seus dirigentes são nomeados pelo Presidente da República, após aprovação pelo Senado, sendo a agência vinculada ao Ministério encarregado pelas políticas públicas para a matéria, sem que haja, todavia, relação de subordinação, assim como ocorre com as demais entidades da Administração Pública indireta, se diferenciando dos demais entes autárquicos de natureza não-especial, em grande parte, por seu atributo sancionador.

Salienta-se, portanto, que a ideia lançada pelo legislador, de utilização do termo "agência" nas legislações de criação dessas autarquias com poderes regulatórios, foi a de transmissão da noção de maior eficiência e adoção de mecanismos de melhor gestão administrativa, sem, contudo, traduzir na exata forma como estes entes funcionam nos demais países do mundo e na acepção original do termo (ARAGÃO, 2013, p. 277 e 278).

0 caráter legalista da administração pública brasileira, insculpida sob o princípio constitucional da legalidade, assim, pode ser considerado como um limitador ao progresso do modelo institucional das agências reguladoras. Sobre o tema, Maria Sylvia Zanella Di Pietro ensina que há aqueles que defendem uma maior flexibilização do sistema jurídico brasileiro, visando a possibilitar maior eficiência às agências:

Sob inspiração do direito estrangeiro, os adeptos da Reforma da Administração Pública propugnam pela ampliação da discricionariedade: a ideia de substituir a Administração burocrática pela Administração gerencial depende, em grande parte, do reconhecimento de maior liberdade decisória aos dirigentes; por isso se diz que o Direito Administrativo atrapalha as reformas, porque ele se apoia no princípio da legalidade, que exige lei para dar fundamento a decisões administrativas; o princípio da legalidade também "atrapalha" a função normativa das agências reguladoras. (...)

De outro lado, há a tendência também bastante forte, calcada no direito positivo e na Constituição, que defende maiores limites à discricionariedade administrativa, exatamente pelo fato de que a sua atuação tem que ter fundamento na lei, mas também tem que observar os limites impostos pelos princípios e valores adotados explícita ou implicitamente pela Constituição (DI PIETRO,2018, p. 49).

Certamente, o poder de editar normas é a mais polêmica das atribuições conferidas às agências. Tem-se que, em muitas vezes no cotidiano, é difícil a verificação da divisão exata entre o que é discricionário e lícito às agências regularem, por se tratar de assuntos técnicos, e o que deveria ser disciplinado exclusivamente no âmbito do Poder Legislativo. A título meramente ilustrativo, cite-se recente discussão sobre a edição da Resolução ANAC n 400/2016. Referido diploma normativo trazia regras a respeito do pagamento de taxas sobre o transporte de bagagens em voos domésticos e internacionais, sendo certo que o transporte de pessoas e de bagagens em voos nacionais e internacionais é 
umas das matéria de competência da Agência Nacional de Aviação Civil - ANAC (art. $8^{\circ}$ da Lei $\left.\mathrm{n}^{\circ} 11.182 / 2005\right)$, encontrando-se, pois, dentro do arcabouço de regulamentação do setor da aviação civil nacional. Porém, representantes no Congresso Nacional tentavam, desde a entrada em vigência da referida resolução, a sustação de seus efeitos, com o argumento de que tais regras eram prejudiciais à população usuária do transporte aéreo. A discussão durou cerca de três anos, até o assunto chegar ao Presidente da República que, no momento da apreciação do projeto de lei que resultaria na edição da Lei $\mathrm{n}^{\circ}$ 13.842, de 2019, contendo alterações que tinham o condão de sustar a referida regra da ANAC, vetou o dispositivo, fazendo com que as regras anteriormente editadas pela agência reguladora fossem corroboradas. Como este, assuntos regulatórios, ordinariamente, entram na pauta do legislativo, sob o argumento de que a decisão tomada pela agência é pretensamente prejudicial a população, justificando-se a ação do Legislativo. Todavia, ignora-se o fato de que as normas são pautadas em estudos de viabilidade técnica, econômica e, sobretudo, no estudo do impacto regulatório, elemento inserido pela Lei Geral das Agências Reguladoras, conforme se terá a oportunidade de comento adiante.

Dessa forma, durante todo o período de impasse entre a agência, representantes do Parlamento e representantes do setor regulado, havia incerteza acerca da continuidade da norma, o que, por certo, pode ter inibido o crescimento e investimentos por parte do setor. Essa interferência em assuntos regulatórios é exemplo de como o modelo funciona no Brasil, ou seja, limitado às Leis emanadas pelo Congresso Nacional, o que, por muitas vezes, pode gerar insegurança jurídica e econômica por parte dos agentes atuantes no mercado.

Modernamente, a fim de ultrapassar problemas como o exposto, a doutrina desenvolve estudos complexos a respeito do conteúdo, sentido e alcance do Princípio da Legalidade, interpretando-o de maneira a se adequar ao Direito Administrativo Contemporâneo e a nova relação entre Estado (na sua função gestora e prestacional) e administrados, criando leituras que distinguem as diversas acepções da Lei, conferindo-lhe um sentido formal e outro material (BARROSO, 2002, p. 306). Estes sentidos estão intrinsecamente ligados à forma como entram em vigência, ou seja, o seu processo de criação.

Por Lei em acepção formal, entende-se aquela advinda de um parlamento, ou seja, oriunda diretamente daqueles que foram eleitos e/ou ocupam a função especifica de produzi-las. Em seu aspecto material, é a que versa sobre temas, genéricos e abstratos, possuindo caráter erga omnes (TAVARES, 2018, p.1036 e 1037). Dessa maneira, ambas as acepções legislativas podem ser genéricas e abstratas, mas apenas a lei em sentido formal pode, com validade, inovar o ordenamento jurídico, por ter vindo daquele que tem a função singular de produzi-la (o Parlamento). Tem-se, aí, o real conceito de "lei" descrito no inciso II do art. 5 da Carta Constitucional (SAVONITTI MIRANDA, 2007a, p. 87; MELLO, 2010, p. 214 e s.) e a real limitação normativa para as agências reguladoras no Brasil. Vê-se, portanto, uma das tentativas criadas para melhor adequação, por parte do sistema rígido da Civil Law, às demandas populacionais, de melhor eficiência da Administração. Assim, restaria às agências a criação de normas infralegais, que podem até ser chamadas de "lei em sentido material", mas sem ser propriamente "leis", na concepção ontológica do termo.

No entanto, é certo, também, que o Princípio da legalidade é fundamental e foi uma grande conquista para a sociedade, possuindo a nobre função de limitar o uso do poder por parte dos administradores, buscando impedir abusos e desvios no trato com a coisa pública e, portanto, não deve ser simplesmente abandonado, ou tanto criticado por aqueles que defendem uma maior eficiência da administração, buscando inserir, cada vez mais, institutos do setor privado na gerência dos órgãos públicos. Constata-se que estes dois princípios, eficiência e legalidade, são a parte de um todo e devem ser observados conjuntamente. É dizer, assim, que a eficiência só é legitima se legal, ou seja, dentro do ordenamento jurídico e, da mesma forma, a legalidade implica em eficiência, sob pena de injustiças. Portanto, o modelo das agências é importante para a dinâmica econômica dos agentes regulados, assim como para a população, que preza pela melhor prestação dos serviços públicos.

\section{O NOVO MARCO REGULATÓRIO BRASILEIRO}

Visto a gênese do modelo regulatório e como ele se adequou a estrutura jurídica brasileira, 
importante salientar os recentes avanços legislativos na área. As agências reguladoras, como integrantes do Poder Executivo, são propensas à interferência política em sua gestão, podendo ter dirigentes nomeados a partir de meras indicações políticas. Além disso, sua má gestão, pautada em interesses escusos e individuais de tais dirigentes, poderia beneficiar exclusivamente os próprios interesses do regulado, excluindo-se a sociedade do debate sobre suas normas.

A fim de evitar que isso ocorra, foi editada a Lei $n^{\circ} 13.848$, de 25 de junho de 2019, que traz o novo marco regulatório brasileiro. Salienta-se que referida lei era aguardada pelo setor regulatório desde o período de criação das primeiras agências no Brasil. A lei trouxe regras, em especial, no que tange a limitar interferências políticas nas agências, além de estabelecer diretrizes voltadas às boas práticas regulatórias.

Pois bem. Inicialmente, destaca-se a regra insculpida no art. $3^{\circ}$ da norma, que define a natureza especial conferida às agências. Nesse sentido, como já tratado: "A natureza especial conferida à agência reguladora é caracterizada pela ausência de tutela ou de subordinação hierárquica, pela autonomia funcional, decisória, administrativa e financeira e pela investidura a termo de seus dirigentes e estabilidade durante os mandatos" (BRASIL, 2019). Note-se que, como este, vários dispositivos do novo Estatuto já eram tratados nas leis de criação de cada agência reguladora, mas que se encontram agora, compilados em um único diploma legal.

0 processo decisório das agências também foi abordado pelo novo diploma legislativo, que trouxe regras já constantes da Lei $n^{\circ}$ 9.784/1999 que regula o processo administrativo em âmbito federal. Por óbvio, também há presença de regras de caráter constitucional, que se devem ser observadas na prolação de qualquer decisão, como a necessidade de devida fundamentação e adequação aos princípios da proporcionalidade e razoabilidade de eventual sanção imposta, pelo descumprimento de normas regulamentares. A novel demonstra a necessidade de indicação dos pressupostos de fato e direito que embasam a decisão, inclusive no que diz respeito a criação de atos normativos.

Outra importante inovação trazida pelo Novo Marco das agências, prescrita em seu art. $6^{\circ}$, se refere a análise de impacto regulatório (AIR). Trata-se de um estudo que deve ser realizado pela agência com vistas as consequências práticas de suas decisões e, sobretudo, de sua ação reguladora que advém de sua regulamentação em determinado setor. Assim, de se esperar que referidas normas devam estar acompanhadas da AIR, devendo, ainda, que o estudo contenha todos os fundamentos técnicos, econômicos e jurídicos que embasem a conveniência de sua existência. Não obstante, deve-se salientar que as agências regulam mercados com grande repercussão social, o que deve demandar, portanto, um amplo planejamento estratégico a longo prazo para trazer maior segurança ao setor regulado, entendendo-se por razoável tal medida, que visa uma análise social e econômica da norma produzida. Ressalte-se, ainda, a necessidade de deliberações por maioria absoluta dos membros da diretoria da agência, o que, por óbvio, tem a pretensão de limitar o poder dos dirigentes e diminuir, por conseguinte, arbitrariedades.

Outra medida trazida pela Lei $\mathrm{n}^{\circ} 13.848 / 2019$ foi a necessidade de prestação de contas e o controle social. Em verdade, as agências, como qualquer outro ente da administração indireta, já eram obrigadas a prestar contas, tanto internamente para órgãos como a ControladoriaGeral da União, quanto externamente para o Congresso Nacional com apoio do Tribunal de Contas da União. Todavia, o termo "controle social" das ações reguladoras ainda não havia sido referendado pela legislação, razão pela qual merece maior destaque. O Controle Social se relaciona a garantia de maior transparência à atividade desenvolvida pelas agências, como promoção de audiências públicas e debates acerca da agenda reguladora e dos normativos que estão sendo estudados para implementação.

0 termo agenda reguladora também foi trazido pela Lei Geral das agências reguladoras. Sua finalidade foi estabelecer um plano de ação, por parte da agência, para planejamento, de longo prazo, das ações de regulação a serem adotadas (BRASIL, 2019).

Mais adiante, a lei traz a possibilidade de interação entre as agências reguladoras e órgãos de defesa da concorrência. Neste tema, observase que as agências possuem competência para instituir normas a fim de possibilitar, cada vez mais, a abertura do mercado para novas empresas 
e a de verificação da "saúde financeira" dos entes regulados. Todavia, as agências fiscalizam a execução dos serviços prestados pelos regulados, não podendo interferir, diretamente, na livre concorrência dos agentes econômicos, limitandose, tão somente, a propiciar um cenário harmônico para atuação dos agentes econômicos, ficando a fiscalização da concorrência, em si, adstrita aos órgãos competentes, como o Conselho de Administração de Defesa Econômica (CADE).

Não há como se negar o caráter integrativo dado pela nova Lei das agências, destacandose, além da relação acima, a possibilidade de articulação entre as próprias agências reguladoras, hipótese que ainda não era prevista na legislação, com possibilidade de edição de atos em conjunto para temas de interesse em comum dos entes reguladores - trazida pelo art. 29 - com a possibilidade, ainda, de solução de conflitos decorrentes da atividade fiscalizadora por meio da mediação e arbitragem entre as agências envolvidas ( $\$ 2^{\circ}$ do art. 29). Há, também, possibilidade de articulação das agências com órgãos de proteção ao meio ambiente e de defesa do consumidor. Sobre este último, como já dito neste ensaio, o papel das agências não é se confunde com as proteções consumeristas, mas sim de fiscalização e regulação técnica do serviço prestado pelo regulado, razão pela qual se mostra bastante oportuna tal interação. Por fim, há possibilidade de interação com as agências estaduais e municipais, o que, por sua vez, não pode significar delegação de competência entre agências de diferentes unidades federativas que tratem de mesma matéria, como ocorre na vigilância sanitária, por força da lei em comento. É dizer que esta se refere a interação apenas operacional.

Por fim, destacam-se as mais importantes mudanças trazidas pela Lei $\mathrm{n}^{\circ} 13.848 / 19$, quais sejam, as referentes à redução das interferências políticas, requisitos mínimos para investidura dos dirigentes e das vedações à investidura nos cargos. Além da estabilidade fixa aos dirigentes, a Lei unificou o prazo de mandado de exercício de cargo de direção para todas as agências e trouxe nova regra: a de necessidade de elaboração de uma lista tríplice produzida por um comitê técnico para que a escolha do Presidente da República seja limita às atribuições técnicas do candidato, sendo, apenas depois, referendada a escolha pelo Senado, constituindo-se em interessante solução visando a redução de eventuais ingerências políticas. Nada obstante, a Lei Geral incentiva a adoção de mecanismos de complience, o que também já é utilizado nas grandes empresas do setor privado. Tal mecanismo tem a função de incentivar atos de conformidade com as normas e leis que regem a agência, ou seja, um mecanismo de repúdio à corrupção.

Quanto aos requisitos mínimos e impeditivos para investidura em cargo de diretoria de agência, há necessidade de comprovação de experiência no setor por, pelo menos, 10 (dez) anos, o que demonstraria um "notório saber técnico" sobre o respectivo setor regulado. Referido dispositivo transmite maior legitimidade do ocupante da vaga à sociedade, que, cada vez mais, demanda pela ausência de ingerências políticas em setores essencialmente técnicos. Também há maior segurança ao setor dado a existência de uma presunção de que as decisões serão tomadas baseadas em aspectos técnicos, não políticos. Além disso, fica impedida a indicação, para a diretoria das agências, de uma série de agentes políticos (como Ministros de Estados, Secretários Municipais e Estaduais, e parlamentares), dirigentes sindicais e partidários, bem como de quem haja atuado, nos últimos 36 (trinta e seis) meses, como participante de estrutura decisória de partido político ou em trabalho vinculado a organização, estruturação e realização de campanhas eleitorais.

Ressalta-se, ainda, o período de "quarentena" que os dirigentes devem passar após a saída dos cargos de direção da agência, que passa de 4 (quatro) para 6 (seis meses), com o objetivo de evitar vantagens indevidas à determinada empresa do setor. Tal mecanismo tem a função, portanto, de garantir maior isonomia entre os regulados.

\section{CONCLUSÕES}

Apesar das restrições geradas pelo sistema da Civil Law ao modelo das agências reguladoras, estas se desenvolveram de forma satisfatória no Brasil e seu modelo tende a permanecer e a se ampliar, principalmente com o advento da Lei $\mathrm{n}^{\circ}$ 13.848 , de 25 de junho de 2019, que criou um programa de diretrizes gerais a serem seguidas pelas agências, com vistas a, especialmente, garantir a atuação técnica das agências e diminuir ingerências políticas. 
0 estudo realizado demonstra que, não obstante o modelo original, baseado nos países da Common Law, ter sido o pilar para as agências brasileiras, estas conseguem realizar suas atribuições legais de forma satisfatória e se desenvolverem de acordo com a sistemática normativa nacional.

Apesar dos percalços jurídicos, juntamente com inconvenientes causados pela adaptação de modelos estrangeiros ao ordenamento pátrio, a prestação de serviço, bem como a execução das políticas públicas voltadas a população tem bons resultados nos índices internacionais. Sob o aspecto jurídico, o princípio constitucional da legalidade, que deve reger todas as atividades administrativas, é, talvez, o maior dos problemas enfrentados pelas agências na sua atividade reguladora.

Ademais, a globalização é fenômeno chave para se explicar o instituto da regulação. Por meio de políticas econômicas mais liberais, a atividade de exploração do capital é deixada, na sua titularidade, à iniciativa privada. Com isso, o ente público deve ater-se a regulação dessas atividades, que pode se dar, inclusive, no cenário internacional. Por conseguinte, resta a adequação dos modelos jurídicos nacionais, que muitos já consideram ortodoxos, frente à economia internacional contemporânea.

A demonstração dos fenômenos que regem o Direito Regulatório no Brasil e suas peculiaridades foram objetivos neste ensaio. A economia neoliberal foi o fator fundamental para o surgimento das agências, por isso a forte influência dos Estados Unidos acerca do modelo das agências no Brasil.

Por fim, nota-se que as agências reguladoras já estão enraizadas no cenário econômico e jurídico do país, razão pela qual cabe aos operadores do Direito a criação de soluções jurídicas para adequação do modelo ao ordenamento. O aperfeiçoamento da gestão e do modelo regulatório e fiscalizatório devem ser buscados a partir de intercâmbios técnicos entre as agências e o sempre necessário aperfeiçoamento da legislação sobre o tema.

\section{BIBLIOGRAPHY}

- ARAGÃo, Alexandre Santos de. As Agências Reguladoras e a Evolução do Direito Administrativo Econômico. 3a Ed. Rio de Janeiro: Forense, 2013.

- CARVAlHO FILHO, Jose dos Santos. Manual de Direito Administrativo. 31 ${ }^{a}$ Ed. São Paulo: Atlas, 2017.

- DI PIETRO, Maria Zanella Sylvia. Direito Administrativo. $31^{a}$ Ed. Rio de Janeiro: Forense, 2018.

- MELLO, Oswaldo Aranha Bandeira de. Princípios Gerais de Direito Administrativo Vol. 1. 3 ${ }^{\underline{a}}$ Ed. São Paulo: Malheiros Editores, 2010.

- MOREIRA NETO, Diogo de Figueiredo. Curso de Direito Administrativo. 16 $\mathrm{a}$ Ed. Rio de Janeiro: Forense, 2014.

- NOHARA, Irene Patrícia. Direito Administrativo. 8 ${ }^{\underline{a}}$ Ed. São Paulo: Atlas, 2018.
- PALMA, Rodrigo Freitas. Antropologia Jurídica. 1a Ed. São Paulo: Saraiva, 2019.

- REALE JÚNIOR, Miguel. Casos de Direito Constitucional. 1aㅡ Ed. São Paulo: Revista dos Tribunais, 1992.

- RAMAlHO, Pedro Ivo Sebba (org.). Regulação e Agências Reguladoras. 1a Ed. Brasília: Anvisa, 2009.

- SAVONITTI MIRANDA, Henrique. Curso de Direito Administrativo. 5a Ed. Brasília: Senado Federal, 2007a.

- SAVONITTI MIRANDA, Henrique. Curso de Direito Constitucional. 5aㅡ Ed. Brasília: Senado Federal, 2007b.

- SAVONITTI MIRANDA, Henrique. Prefácio. In: SAVONITTI MIRANDA, Henrique (Coord.) Tratado de parcerias públicoprivadas. Tomo II - PPPs e o Direito Comparado. Rio de Janeiro: Centro de Estudos Empírico-Jurídicos, 2019. 
- TAVARES, André Ramos. Curso de Direito Constitucional. 16 Ed. São Paulo: Saraiva, 2018.

- TOMAZETTE, Marlon. Direito Societário e Globalização: Rediscussão da Lógica Público-Privada do Direito Societário diante das Exigências de Mercado Global. 1a Ed. São Paulo: Atlas, 2014.

- CANOTILHO, J. J. Gomes; MENDES, Gilmar F.; SARLET, Ingo W.; STRECK, Lenio L. (Coords.). Comentários à Constituição do Brasil. 2ª Ed. São Paulo: Saraiva/Almedina, 2013.

- BARROSO, Luís Roberto. Agências Reguladoras. Constituição, Transformação do Estado e Legitimidade Democrática. Revista de Direito Administrativo. $\mathrm{n}^{\circ}$ 229, Jul/Set, 2002.

- CARNEIRO, Ruy de Jesus Marçal. Reflexões sobre a não-intervenção do Estado na "atividade econômica", nos termos do art. 173 da vigente Constituição Federal. Revista do Direito Público. V. 1, n. 1, 2006.

- GONÇALVES, Jonas Rodrigo. Como escrever um Artigo de Revisão de Literatura. Revista JRG de Estudos Acadêmicos, Ano II, Vol.II, n.5, 2019.

- GONÇALVES, Jonas Rodrigo. Manual de Artigo de Revisão de Literatura. 2.ed. Brasília: Processus, 2020.

- GONÇALVES, Jonas Rodrigo. Metodologia Científica e Redação Acadêmica. 6.ed. Brasília: JRG, 2015.

- GROTTI, Dinorá Adelaide Musette. Agências Reguladoras. Revista de Direito Administrativo. Ano 8, n 10, 2004.

- OLIVEIRA. Rafael Carvalho Rezende. O Modelo Norte-Americano de Agência Reguladoras e sua Recepção pelo Direito Brasileiro. Revista da EMERJ. V. 12, n ${ }^{\circ} 47$, 2009.

- SOUTO, Marcos Juruena Villela. Agências Reguladoras. Revista de Direito Administrativo. ${ }^{\circ}$ 216, abril/junho 1999.

- BRESSER-PEREIRA. Luís Carlos. A Reforma
Gerencial do Estado de 1995. Revista de Administração Pública. V. 34, n ${ }^{\circ}$, 2000.

- MATOS, Fernanda Laís; Costa, Isabel Soares; Xavier, Yanko Marcius de Alencar. Regulação e Agências reguladoras nos Estados Unidos da América e suas Influências para a Industria do Petróleo no Brasil. $3^{\circ}$ Congresso Brasileiro de P\&D em Petróleo e Gás. 2005. Disponível em - http://www.portalabpg.org.br/ PDPetro/3/trabalhos/IBP0598_05.pdf visualizado em 03/04/2019.

- BRASIL. Constituição da República Federativa do Brasil. Promulga a Constituição do Brasil. Diário Oficial da União, Brasília, Seção 1, p. 1, de 5 de outubro de 1988.

- BRASIL. Lei $\mathrm{n}^{\circ}$ 9.784, de 29 de janeiro de 1999. Regula o processo administrativo no âmbito da Administração Pública Federal. Diário Oficial da União, Brasília, Seção 1, p. 1 de 01 de fevereiro de 1999.

- BRASIL. Lei $\mathrm{n}^{\circ} 11.182$, de 27 de setembro de 2005. Cria a Agência Nacional de Aviação Civil - ANAC, e dá outras providências. Diário Oficial da União, Brasília, Seção 1, p. 1, de 28 de setembro de 2005.

- BRASIL. Lei ${ }^{\circ} 13.848$, de 25 de junho de 2019. Dispõe sobre a gestão, a organização, o processo decisório e o controle social das agências reguladoras, altera a Lei $n^{\circ}$ 9.427, de 26 de dezembro de 1996, a Lei no 9.472, de 16 de julho de 1997, a Lei no 9.478, de 6 de agosto de 1997, a Lei no 9.782, de 26 de janeiro de 1999, a Lei no 9.961, de 28 de janeiro de 2000, a Lei $n^{-}$9.984, de 17 de julho de 2000, a Lei no 9.986, de 18 de julho de 2000, a Lei no 10.233, de 5 de junho de 2001, a Medida Provisória no 2.228-1, de 6 de setembro de 2001, a Lei no 11.182, de 27 de setembro de 2005, e a Lei no 10.180, de 6 de fevereiro de 2001. Diário Oficial da União, Brasília, Seção 1, p. 1, edição 121, de 26/06/2019.

- BRASIL. Lei $\mathrm{n}^{\circ} 13.842$, de 17 de junho 
de 2019. Altera a Lei $n^{\circ}$ 7.565, de 19 de dezembro de 1986 (Código Brasileiro de Aeronáutica). Diário Oficial da União, Brasília, Seção 1, Edição Extra - A, de 17 de junho de 2019.

- BRASIL. Resolução ANAC n 400, de 13 de dezembro de 2016. Dispõe sobre as Condições Gerais de Transporte Aéreo. Diário Oficial da União, Brasília, Seção 1, Edição 239, p. 104, de 14 de dezembro de 2016. 